\title{
Menstruation During a Lifespan: A Qualitative Study of Womens Experiences
}

\author{
Ida Emilie Brantelid, Helena Nilver and Siw Alehagen
}

\section{Linköping University Post Print}

\section{Tweet}

N.B.: When citing this work, cite the original article.

This is an electronic version of an article published in:

Ida Emilie Brantelid, Helena Nilver and Siw Alehagen, Menstruation During a Lifespan: A Qualitative Study of Womens Experiences, 2014, Health Care for Women International, (35), 6, 600-616.

Health Care for Women International is available online at informaworldTM:

http://dx.doi.org/10.1080/07399332.2013.868465

Copyright: Taylor \& Francis (Routledge): STM, Behavioural Science and Public Health Titles http://www.routledge.com/

Postprint available at: Linköping University Electronic Press

http://urn.kb.se/resolve?urn=urn:nbn:se:liu:diva-109161 
Menstruation during a lifespan:

A qualitative study of women's experiences

Ida Emilie Brantelid, Helena Nilvér and Siw Alehagen

Linköping University

\begin{abstract}
Author note
Ida Emilie Brantelid, Linköping, Sweden; Helena Nilvér, Linköping, Sweden; Siw Alehagen, Department of Medical and Health Sciences, Division of Nursing Science, Faculty of Health Sciences, Linköping University, Linköping, Sweden
\end{abstract}

No foundations have been involved in this study.

The authors wish to thank the women who participated in this study. We thank Octavio Vargas for his reflections and comments during the research process and when writing the manuscript.

Correspondence concerning this article should be addressed to: Siw Alehagen, Division of Nursing Science, Department of Medical and Health Sciences, Faculty of Health Sciences, SE-582 85 Linköping, Sweden. E-mail: siw.alehagen@liu.se 


\begin{abstract}
Menstruation is a natural phenomenon for women during their reproductive years. Our aim was to describe women's experiences of menstruation across the lifespan. Qualitative interviews, with a narrative approach, were conducted with 12 women between 18 and 48 years of age in Sweden. Using thematic analysis, we found menstruation to be a complex phenomenon that binds women together. It is perceived as an intimate and private matter, which makes women want to conceal the occurrence of menstrual bleeding. Over time, menstruation becomes a natural part of women's lives and gender identity. Health professionals play a central role supporting women to deal with menstruation.
\end{abstract}

Keywords: menstruation, women's experiences, lifespan, qualitative research, thematic analysis 
Menstruation is a natural phenomenon for women of fertile age and is a unique experience for women during their reproductive years. Midwives and other health professionals need to understand menstruation as a natural phenomenon in women's lives in order to talk about and give support regarding issues like sexuality, contraception, fertility, puberty and menopause. In Sweden, the midwife plays a central role in questions regarding sexual and reproductive health by meeting women throughout their lifespan. From a secondary analysis by Lundgren and Berg (2007) concerning the central concepts in the midwife-woman relationship, the researchers described how the midwife needs to support the specific, individual needs of a woman in order to create a mutual and supportive relationship with her.

Over almost 40 years, menstruation is a part of female life. It starts from menarche, a girl's first menstrual bleeding, which takes place at the mean age of 13, and continues until menopause, a woman's last menstrual bleeding, which occurs at 52 years of age on average (Reece \& Barbieri, 2010). Many researchers have focused on these two periods. Menarche is associated with sexual maturation, symbolizes the transition from childhood to womanhood and is a unique experience for every woman. However, many young girls express sadness at not being ready to become a woman when reaching menarche (Lee, 2009; Orringer \& Gahagan, 2010; Rembeck \& Hermansson, 2008; Uskul, 2004). Menopause is a part of the midlife changes. It is a natural period in the female lifecycle, a phase allowing self-realization, and positive feelings have been described in relation to the cessation of menses (Ballard, Kuh \& Wadsworth, 2001; Berterö, 2003; George, 2002; Lindh-Åstrand, 2007).

Information about menstruation is mostly obtained from mothers, schoolteachers (Amaral, 2011; Beausang \& Razor, 2000; Rembeck \& Hermansson, 2008), friends (Amaral, 2011; Kissling, 1996) and older sisters (Amaral, 2011). The menstrual education that women receive 
can influence their attitudes toward menstruation and sexuality (Beausang \& Razor, 2000; Rembeck \& Gunnarsson, 2004). The teenage years can be a time of physical and social changes, which may lead to girls feeling a greater need for integrity (Rembeck \& Hermansson, 2008) and not wanting bodily attention. This may result in girls experiencing feelings of being objectified and a sense of losing control of their bodies. By learning to manage their own menstruation, obtaining knowledge about it and creatively responding to menstrual norms, girls can reassert this control (Fingerson, 2005).

Social and cultural factors may play a central role in menstrual knowledge (Orringer \& Gahagan, 2010); cultural beliefs may give rise to the idea that menstruation is a secretive female process (Beausang \& Razor, 2000; Johnston-Robledo \& Chrisler, 2013). JohnstonRobledo and Chrisler (2013) argue that this is a stigma that may affect women's body image and sexual health. Menstruation is generally described as intimate (Amaral, 2011) and as a phenomenon that should be kept hidden from others (Amaral, 2011; Lee, 2009; Marván \& Trujillo, 2010). Studies from different parts of the world indicate the existence of social rules that require the concealment of menstruation, which may result in continuing stress for women (Çevirme, Çevirme, Karaoglu, Urgurlu \& Korkamaz, 2010; Johnston-Robledo \& Chrisler, 2013; O’Flynn, 2006; Sommer, 2009; Uskul, 2004). Moreover, attention should be paid to the social context in which women live and to the obligations to follow expected social rules that they feel (O’Flynn, 2006). In a multiethnic study by Orringer and Gahagan (2010), it was asserted that social and cultural factors appear to play a central role concerning how menstrual knowledge is communicated to young girls.

Women often refer to menstruation in negative terms as shameful and embarrassing (Çevirme et al., 2010; Lee, 2009). Negative feelings surrounding menstruation are also expressed when 
having sexual intercourse during menstrual bleeding. It is experienced as bloody, messy and disgusting by some women, while other women describe it with more neutral or positive terms (Allen \& Goldberg, 2009; Fahs, 2011; O’Flynn, 2005).

Pain related to menstruation as well as heavy menstrual bleeding, irregular menstruation and premenstrual syndrome are the subjects of many descriptions of menstruation. Women reduce their social activities and adapt their lives in order to manage heavy menstrual bleeding and severe pain (Santer, Wyke \& Warner, 2007; O’Flynn, 2006). Furthermore, there seems to be a correlation between severe menstrual pain, irregular menstrual cycles and heavy menstrual bleeding on the one hand and psychosocial stress on the other (Barnard, Frayne, Skinner \& Sullivan, 2003; Yamamoto, 2009), which may result in a poorer health status (Barnard et al., 2003). Scholars indicate that women with a negative and bothersome experience of menstruation are more positive to menstrual suppression than women with more positive attitudes (Andrist, 2004; Johnston-Robledo, Ball, Lauta \& Zekoll, 2003).

Menstruation is a central part of women's lives regarding sexual and reproductive health. However, surprisingly few researchers have focused on women's experiences of menstruation during their reproductive years. Midwives and other health professionals need knowledge about the menstrual phenomenon in order to support the unique experiences of menstruation and to help women develop better awareness of their own body. Our aim in this study was to describe women's lived experiences of menstruation as a phenomenon during the female lifespan focusing on the influences of work life, social life, family and partner, and body. 


\section{Method}

To obtain a deeper understanding of women's lived experiences, we chose a narrative approach, as it is a fundamental form of communication between humans. It has developed into a method to collect data in qualitative research, as it gives access to the participants' lived experiences (Riessman, 2008). Furthermore, thematic analysis made it possible for us to see themes emerge within the data set. By using a latent approach, we could identify and examine underlying ideas and assumptions giving us unanticipated insights (Braun \& Clarke, 2006).

\section{Participants}

Twelve women between 18 and 48 years of age (median, 35.5 years) in Sweden were interviewed; a wide age range was chosen in order to obtain a sample representing the time span in which women menstruate. Inclusion criteria were as follows: experience of menstruating and speaking Swedish fluently. The study was carried out in a medium-sized university city in Southeast Sweden. Seven women were either married or lived together with their partner, and five women lived without a partner. Five of the women did not have children and seven had one or more children. Two women had completed nine years of compulsory education, four had completed upper secondary school and six women had completed university studies. All of the women were native Swedish.

\section{Procedure}

The interview questions were tested with the help of two women and some problems broadening and obtaining in-depth narratives were identified. By using stimulus material, participants can be encouraged to tell their stories (Törrönen, 2009). Therefore, visual stimulus material was developed, which involved a picture of a woman surrounded by text referring to four subjects: work life, social life, family and partner, and body. In order to 
obtain good validity, the stimulus material was shown and discussed to eight women who did not participate in the study. After that small adjustments of the stimulus material were made. Finally, one test interview was conducted by each of two of the authors (I.B., H.N.) and, to ensure validity, the interviews were discussed with the third author (S.A.). Both of these test interviews were included in the study.

Women were recruited through snowball inclusion and the sampling was made purposeful to the aim of the study by recruiting women of different socioeconomic backgrounds and ages. We asked some students and acquaintances to ask their friends and relatives about their willingness to participate, and six snowballs were started. The interviews were booked continuously and, if women were interested in participating, they received written information about the study, in which ethical considerations were represented. Participants chose the settings in which they were to be interviewed. Six were performed in private rooms at a public library, four in women's homes, one at the woman's workplace and one at a university.

In total, six interviews were conducted by each interviewer (I.B., H.N.); they lasted from 22 to 62 minutes (median, 39 minutes). The interviews were conducted from October 2011 until January 2012. Two open-ended questions were used. The first question was, "Can you tell me how it was when you had your first menstruation?" The next question was connected with the stimulus material with the picture of a woman surrounded by text of the four subjects: work life, social life, family and partner, and body. The question was, "Can you tell me how it is for you during your period thinking about these four subjects?” Participants looking at the stimulus material were encouraged to speak freely and additional questions such as, "Can you tell me more?" and "How did you react/feel in this situation?" were asked in order to deepen the narratives. The interviews were tape-recorded and then transcribed by the interviewer. 


\section{Data Analysis}

The text was analysed according to Braun and Clarke's (2006) step-by-step guide to thematic analysis, which includes five steps. The analysis was carried out by two of the authors (I.B., H.N.) and, during the process, discussed with the third author (S.A.), which strengthened its credibility.

1. Familiarization with the data set was achieved by reading the text repeatedly to ensure accuracy. 2. Systematic coding was made of all data that appeared interesting and referred to the most basic elements of the raw data. Equal attention was paid to each data item; individual data items were assigned a single code and several codes appeared. Potential patterns then started to emerge. 3. The codes and patterns were sorted into possible themes. This was carried out manually by making an initial thematic map. Some initial codes became main themes, others became sub-themes and some were excluded as they did not correspond to the aim of our study. 4. In the next phase of the analysis, the themes were studied to ensure the validity of individual themes, how they were correlated to each other, and that they represented the narratives and were relevant to the aim of the study. 5. Furthermore, the essence of each theme was identified by defining and refining the names of the themes and what they were about, as well as the themes overall. Finally, extracts were selected that clarify the essence of the themes (Braun \& Clarke, 2006).

\section{Ethical Considerations}

The study was carried out in accordance with the World Medical Association Declaration of Helsinki (2009) and the Swedish Code of Statutes (2003) to maintain confidentiality and integrity. Participants received both written and oral information about the aim of the study, the approach, how the material would be used, that they participated on a voluntary basis and 
that they could withdraw at any time. Before starting the interview, each participant provided written informed consent. Throughout the working process, the material was handled confidentially and identifiable material was not used. The consequences for the participants were considered from their own perspectives to ensure they would suffer no harm during the research process. Women have received fictive names when cited in the text.

\section{Results}

In the analysis, we identified three main themes from the participants' narratives: belonging and confidence, intimacy and concealment, and menstruation as a part of life. Each theme is supported by two to three sub-themes (Table 1).

\section{Insert Table 1 here}

\section{Belonging and Confidence}

This theme is based upon the continual underpinning presence of support and bonding between women, which creates identity between all women who have menstruated. The theme consists of two subthemes: menstrual support and knowledge, and female bonding.

Menstrual support and knowledge: In the narratives, one's mother is described as a key person who influences the experience of menarche and menstruation. She is the first person the women turn to for emotional and practical support and knowledge. In a supportive relationship, the mother makes menstruation a natural issue that can be openly discussed. Furthermore, the mother has a more profound role in that she facilitates the transition whereby a young woman finds confidence in her new identity. The mother's emotional support and understanding help the woman to find her inner strength that entails her becoming able to look 
upon herself as a menstruating woman. In contrast, for those women who receive inadequate support and menstrual knowledge, the experience of menstruation becomes more difficult. Frida (27 years) describes how she was uncomfortable talking with her mother about menstruation. For instance, this resulted in her not knowing what sanitary product to use, leading to menstrual leakage at school.

If women feel they can talk openly about menstruation with their mothers, it becomes more natural for them to do so throughout their lifespan and strengthens their confidence. In addition, it is then easier to communicate menstrual knowledge to their siblings and later on to their own children.

For her, it's a really open topic because it's so natural and everyone has it. That's probably why I can be open with my sister about it, too, because that's what mum did with me (Sara, 18 years).

In contrast, some women feel inhibited in talking about menstruation because they have not learned the social context in how to communicate the menstrual. Beyond mothers, friends are an important source of menstrual knowledge and support. For instance, Elisabeth (42 years) describes how she and her female colleagues at work support each other and share menstrual information during their periods.

Female bonding: Special bonds between women are revealed as constituting a female community that includes all those who have experienced menstruation. From these female bonds, there is support and mutual understanding between women, which implies that they can share menstrual experience and knowledge; thus, a sense of coherence is obtained. The 
women describe how as girls they did not feel they belonged to the female group until they became aware that other girls were also menstruating.

I suppose you could say that you felt a sense of belonging regarding your period as well, because all your friends had it (Katarina, 37 years).

Women feel they can share and relate to menstruation because they are aware that it is a part of female identity. There is an underlying assumption between women that they should help each other maintain privacy regarding menstruation by offering sanitary products and analgesia if needed. When experiencing menstruation, women understand each other, they become closer and, as described by Sara (18 years), they start to speak the same language. Furthermore, Sara describes how a friend offered her a spare pair of trousers in order to conceal her menstrual leakage at school.

Women assume that premenarcheal girls or men do not have the same ability to understand the phenomenon of menstruation because they have not experienced menstrual bleeding. Men in particular, for instance, fathers, are therefore excluded from the female bond, and the women describe being uncomfortable talking about menstruation in their presence.

Well, every woman menstruates. But still it's not something you talk directly about. Well, you talk about it between women, but not with men, in any kind of way. I mean, all women get their period. But still, it's nothing you talk about. Well, women talk about it amongst themselves, but not with men, somehow (Jenny, 25 years). 
Some women specifically mention male friends with whom they can share menstrual experiences with and therefore make them part of the female bond. These men already have some understanding of menstruation as they themselves have been able to deepen their menstrual knowledge from close family members like wives and sisters.

\section{Intimacy and Concealment}

This theme is based upon how menstruation on different levels influences the daily lives of the participants. The theme consists of three sub-themes: being exposed, to have but to hide and affecting daily life.

Being exposed: In the narratives, menstrual blood is described in negative terms, ranging from "not being fresh" to "gross" and "disgusting". For instance, some women state how they shower more frequently to maintain a good hygienic standard during their menstrual period.

Well, I don't feel as fresh. I think it's great when your period is finished, finally. That first shower after your period is finished, that feels just great (Frida, 27 years).

Owing to the negative feelings about menstrual blood, women describe how they feel uncomfortable having sexual intercourse during menstrual bleeding and therefore choose not to do so. Furthermore, women express an overall fear and embarrassment associated with visible leakage of menstrual blood. This is because it would be apparent to others that they are menstruating, which for the woman would lead to feelings of being exposed, as an intimate issue for her is visible to others.

With your periods, it's a little bit like, I constantly have to keep it on my mind. If I can't handle it, it will stain and that's not that funny; it's gross and that's how it is. It's a bit like 
that with my period; I need to keep it at the back of my mind constantly. If I don't take care of it properly it will stain, which isn't great, and it's disgusting, sort of like that (Lena, 42 years).

Some women describe it as being stressful not to have the possibility to go to the toilet and change sanitary products when needed. This leads to a fear of menstrual leakage and that someone might notice any odour, which would result in the intimacy of this issue being lost and the generation of feelings of being exposed.

In addition, women express feelings of not wanting their menstruation to seen by men. Some women specifically experience feelings of shame at having to reveal menstruation to their fathers.

To have but to hide: Women experience menstruation as something all females have. However, they still feel obligated to conceal their menstruation from others, except from very close family members and friends. Menstruation is described as an intimate and private matter.

It shouldn't kind of show, it should be, girls should have it but it shouldn't appear as if they do (Cecilia, 21 years).

This can be interpreted as a social norm indicating that menstruation is something that all women should have, but the social context prohibits them from letting anyone else become aware of it. This is described by Jenny ( 25 years). In order to conceal her menstruation from male colleagues, she hides her used sanitary products in her bag instead of throwing them in 
the toilet bin at work. She specifically states how her behaviour and attitudes are being influenced by a social norm.

This social norm is questioned by the women as they feel that menstruation is a natural phenomenon that all women experience and should therefore not have to be concealed. However, women still want to hide their periods, keep them private and choose not to confront the social norm. This is strongly expressed by Lena (42 years). She recalls an incident from when she was young where she observed a friend putting in a tampon in her presence. As Lena had learned that menstruation is an intimate and secret matter, she reacted strongly to this incident. Even today, she questions her strong feelings towards this specific event as she wants to feel that menstruation is something natural and should not have to be concealed. Furthermore, some women with long experience of menstruation are aware of the presence of this social norm, but they do not feel controlled by it. For instance, Gunilla (48 years) says that she followed it when she was younger but now she does not care.

Affecting daily life: Women experience that menstruation and menstrual symptoms affect their activities and performance in daily life. For instance, they experience how their concentration, patience and efficiency at work or in school are reduced, which leads to feelings of not being as productive as expected in the social context. In addition, some women choose not to attend public swimming facilities during menstruation. Sara (18 years) describes a door being closed in terms of not being able to swim when menstruating.

However, some women do not feel it is acceptable to let menstruation affect their daily life, and they describe that this requires continuous mental and practical management. In order to obtain control of their menstrual bleeding, they are therefore prepared with sanitary products 
and have to know where the toilets are if needed. Over time, menstruation becomes routine and requires less mental effort, as women use different strategies to gain control. For instance, Frida (27 years) describes how, with the help of contraceptives, she is able to control her menstrual bleeding. She experiences menstruation as bothersome and feels it is a relief not to think about it during vacations. Furthermore, women describe feelings of relief in relation to the cessation of menstruation, in that they do not have to consider mental and practical management.

I mean, there's nothing negative about getting rid of your period... It's positive because then you don't have to, I mean, think about that time period (Maria, 37 years).

\section{Menstruation as a Part of Life}

This theme is based upon how women describe their menstrual experience as a continuous process, which, step by step, has become a part of their lives and a sign of health. Three subthemes were identified: assurance of a functioning body, a continuous process over time and accepting menstruation.

Assurance of a functioning body: The women relate menstruation to reproductive health and it is described as an assurance of a functioning body and fertility.

Somehow I feel that, when you have your period, then you know that everything works as it should... Or it's more like a confirmation that, well, that everything works as it should. Simple as that (Emma, 25 years).

For the women, menstrual bleeding is experienced as a natural and healthy explanation for having symptoms like cramps or premenstrual symptoms. Several women express concerns regarding missed menstrual periods, which have resulted in some of them seeking healthcare 
to ensure their continuing health. Eva (47 years) expresses how she, when experiencing missed periods, reflected on this as a possible sign of stress, cancer, menopause or pregnancy. In addition, some women gave up contraceptives in order to obtain a better body awareness and to learn more about how their body functions.

I wanted to get to know my own body, sort of, and how it really works. Not how the hormones affect it... to feel that you get your period. Somehow, it's a way of knowing that you sort of have a working menstruation cycle (Jenny, 25 years).

A continuous process over time: Women describe how the experience of menstruation changes over time. Menarche is described as an important part of the transition to womanhood. Some women describe this transition as being associated with feelings of fear, shame and unpleasantness, and of not feeling ready to enter womanhood. In the narratives, it is revealed how they, over the years, have gained new understandings of the menstrual phenomenon compared with their first menstrual experiences. Women explain how they, over time, have learned to adapt to menstruation as a part of their life. When menstruation becomes a part of the female identity, several women describe that they feel it is easier to share menstrual experiences with others and to learn methods of mental and practical management.

Then, as time passes and you get older, it becomes a natural part of your life (Anna, 34 years).

In addition, some women state how they, upon getting older, have reached a point where they no longer experience menstruation as a necessary part of their lives.

You think, when you're done with it and that. I regard my period as something unnecessary; a totally unnecessary condition, right now (Katarina, 37 years). 
Accepting menstruation: Women experience menstruation as a natural part of being a woman and part of their gender identity. They describe menstruation as something that comes every month and, over time, becomes a part of everyday life. Furthermore, women feel they need to accept menstruation and endure menstrual symptoms because it is a phenomenon that cannot be excluded from female life.

In the narratives, there are apparent contradictions; on one hand, women experience menstruation as a positive and natural part of life, whereas on the other hand, it is bothersome and related to negative feelings. Lena (42 years) describes this contradiction and her ambivalent feelings; she has accepted menstruation as a natural part of female life, constituting the physical evidence that you can have children and therefore being a sign of health. However, she still experiences great relief upon the cessation of menstruation. In contrast, Katarina (37 years) personifies her experience of menstruation as a close companion who has been with her over the years.

And somehow I think you learn to live with it. It's a bit like that. You can only accept it, sort of. Periods are part of life and the naturalness of a woman's body (Gunilla, 48 years).

\section{Discussion}

Our findings in this study can contribute to our understanding of the genuine experience of menstruation from women's perspectives across a lifespan. Many previous researchers have focused on specific perspectives of menstruation, like the experience of menarche (Fingerson, 2005; Lee, 2009; Orringer \& Gahagan, 2010), menstrual education (Amaral, 2011; Beausang \& Razor, 2000; Rembeck \& Hermansson, 2008), menstrual symptoms (Johnston-Robledo et al., 2003; Santer et al., 2003; O’Flynn, 2006) or been based on beliefs about and attitudes 
towards menstruation (Marván, Ramírez-Esparza, Cortés-Iniestra \& Chrisler, 2006). Our results, based on women's narratives, reveal the complexity surrounding menstruation as being an experience unique to each woman. Although women express similar thoughts about menstruation, it is still an individual experience as all women are a part of different social contexts.

As found here and supported by other studies (Amaral, 2011; Beausang \& Razor, 2000; Koff \& Rierdan, 1995; Rembeck \& Hermansson, 2008; Uskul, 2004), for women, one's mother is seen as the primary source of information, as well as emotional and practical support, when reaching menarche. Furthermore, we found that one's mother plays an essential role in how women relate to the menstrual phenomenon later in life. We believe that this confirms the importance of the social context in which a young woman lives and how it influences her experiences later in life. With this understanding, health professionals may be more able to support young women in their process of gaining body awareness.

Kissling (1996) found that girls were most comfortable talking about menstruation with their closest girlfriends and that it seemed to increase their solidarity among friends. Through the women's narratives we found that the experience of menstruating can bind the women together, giving them a sense of unity. By experiencing menstruation, women share a mutual understanding and therefore sense that they are part of a wider group. This female bond might play an essential role for each woman as it helps women to find their gender identity, of which menstruation is a part. We have found no other reports of studies that describe women becoming more strongly bonded to female as a group. This might be due to our research aim of focusing on women's experiences of menstruation during their lifespan. However, Fingerson (2005) mentions that menstruating girls, experience a sense of connection with a 
larger group of women. In contrast, Stubbs and Costos (2004) argue that women, who have negative attitudes towards menstruation, may result in feeling disconnected from other women.

Johnston-Robledo and Chrisler (2013) assert that menstruation has a hidden social stigma as it is something women do not want to reveal. It is difficult to tell if a woman is menstruating unless she says so or experiences menstrual leakage on her clothes. This is shown in our study, as women expressed how menstruation is something you should have but should be kept hidden from others. Through shared female experience of menstruation, women help each other to conceal it. This can be seen as a sign of menstruation having a stigma in that it should not visible.

In the analysis, it emerged that, throughout their lifespan, women relate to menstruation as something natural that all women experience and as a sign of health. This implies that menstruation is a natural part of the female identity, which cannot be set aside. Therefore, health professionals need to be aware of the significance that menstruation has for menstruating women. We have found surprisingly few studies focusing on menstruation from a natural perspective (Burrows \& Johnson, 2005; Fingerson, 2005; Marván et al., 2006). If midwives or other health professionals are not able to look upon menstruation from a natural perspective or do not see menstruation as a part of female identity, it might be more difficult for them to support women through their unique and individual experiences of menstruation.

Throughout the narratives, we can see the implications of the social rule that menstrual experiences are something you share with other females, but generally not with men. Women express a continuous need to conceal the presence of their menstrual bleeding as it is 
considered an intimate and private matter. Comparable findings have been revealed in several other studies (Amaral, 2011; Lee, 2009; Marván \& Trujillo, 2010; O’Flynn, 2006). We find it noteworthy that the women in our study question the social rules that they feel obligated to follow. Although they want to resist and go against the social norms, they cannot do so as menstruation is a private and intimate matter. If their menstrual bleeding were revealed to others, they would feel exposed. Johnston-Robledo and Chrisler (2013) assert that a social stigma is attached to menstruation, which can have negative consequences for a woman's body image, self-esteem and sexual health. Other studies (Burrows \& Johnson, 2005; Johnston-Robledo \& Chrisler, 2011) have acknowledged the importance of social norms being challenged and disrupted so that women's experiences of menstruation can change for the better. Health professionals can assist women in their efforts to resist social norms, as described by both Johnston-Robledo and Chrisler (2013) and Burrows and Johnson (2005), which may have a positive impact on their wellbeing. We consider it essential that healthcare professionals are aware of social norms and take the intimacy surrounding menstruation into consideration when meeting with woman, in order to create a good caring relationship.

The women in our study, when reaching menarche, described feelings of not being ready to enter womanhood. This is consistent with the findings from of Beausang and Razor (2000), Fingerson (2005), and Rembeck and Hermansson (2008). In addition, our research indicates how the menstrual experience is a process, which over time becomes a part of the female identity and a natural periodic event. Women reach a point where they accept menstruation as a part of their lives; they have adapted to and accepted the presence of their periods.

Furthermore, as shown in several other studies (Ballard et al., 2001; Berterö, 2003; George, 2002; Lindh-Åstrand, 2007), women, when getting older, reach a phase where they no longer see their menstruation as a necessary part of life and therefore find it natural to enter the 
menopause transition. We consider that, by creating awareness of women's experiences of the menstrual phenomenon, it might be more likely that healthcare providers meet individual women's specific needs when they seek healthcare, and thereby contribute to a more positive experience of menstruation. These findings are unique as we have not found reports of similar research that focused on experiences of menstruation over time; we therefore also suggest the need for further research.

\section{Limitations and Strengths}

The inclusion process was a challenge and a potential limitation as we found it difficult to recruit women from different socio demographic backgrounds. As menstruation is an intimate phenomenon, talking about the stimulus material used in this study might have facilitated the provision of a more extensive narrative. However, it is possible that the text referring to four topics on the stimulus material affected the women's spontaneous thoughts and thereby limited their narratives. An alternative would have been to use focus-group interviews. This may have been a stronger stimulus, but then some of the unique and individual perspectives might have been lost. The narrative approach and thematic analysis were beneficial because they gave us access to the women's individual and lived experiences. By using individual interviews, a rich and broad range of material was obtained, even though only 12 women were interviewed. We could have recruited more women but as the data amount of data was large our decision was to end the inclusion.

To ensure trustworthiness in qualitative research, credibility should be achieved, which confirms how consistent the findings are with reality (Shenton, 2004). This has been accomplished by carefully following the chosen method of analysis and taking ethical principles into consideration. The findings may be transferable to women in a similar cultural 
context, but the transferability is probably limited as the women in the study represent an example within a broader group. However, it is notable that our findings in many ways are correspond to studies with larger samples, conducted in other cultural contexts (Burrows \& Johnson, 2005; Fingerson, 2005).

\section{Conclusion}

We report the results from this research to show that menstruation is a complex phenomenon and it is an experience unique to each woman. When starting to menstruate, women feel more connected to other women and become a part of the female group as a whole. Women are aware of the presence of social norms regarding menstruation that they feel obligated to follow. Over time, women experience how menstruation becomes a natural part of their lives and gender identity.

In conclusion, we contend that many professionals, especially, like health professionals, play a central role in the meeting with women as they have the possibility to acknowledge and confirm paradoxical feelings related to social norms, which would help them to meet individual women's needs. If health professionals are able to provide individualized support that acknowledges the uniqueness of the menstrual phenomenon, they might contribute to a more positive menstrual experience.

\section{References}

Allen, K. R., \& Goldberg, A. E. (2009). Sexual Activity During Menstruation: A qualitative study. Journal of Sex Research, 46, 535-545.

Amaral, M. C. E., Hardy, E., \& Hebling, E. M. (2011). Menarche among Brazilian women: memories of experiences. Midwifery, 27, 203-208. 
Andrist, L. C., Hoyt, A., Weinstein, D., \& McGibbon, C. (2004). The Need to Bleed: Women's Attitudes and Beliefs about Menstrual Suppression. Journal of American Academy of Nurse Practitioners, 16, 31-37.

Ballard, K. D., Kuh, D. J., \& Wadsworth, M. E. J. (2001). The role of the menopause in women's experiences of the 'change of life'. Sociology of Health \& Illness, 23, 397-424.

Barnard, K., Frayne, S. M., Skinner, K. M., \& Sullivan, L. M. (2003). Health Status among Women with Menstrual Symptoms. Journal of Women's Health, 12, 911-919.

Beausang, C. C., \& Razor, A. G. (2000). Young western women's experiences of menarche and menstruation. Health Care for Women International, 21, 517-528.

Berterö, C. (2003). What do women think about menopause? A qualitative study of women's expectations, apprehensions and knowledge about the climacteric period. International Nursing Review, 50, 109-118.

Braun, V., \& Clarke, V. (2006). Using thematic analysis in psychology. Qualitative Research in Psychology, 3, 77-101.

Burrows, B., \& Johnson, S. (2005). Girls' experiences of menarche and menstruation. Journal of Reproductive and Infant Psychology, 23, 235-249.

Çevirme, A. S., Çevirme, H., Karaoglu, L., Ugurlu, N., \& Korkamaz, Y. (2010). The perception of menarche and menstruation among Turkish married women: attitudes, experiences, and behaviors. Social Behavior and Personality, 38, 381-394.

Fahs, B. (2011). Sex during menstruation: Race, sexual identity, and women's accounts of pleasure and disgust. Feminism \& Psychology, 21, 155-178.

Fingerson, L. (2005). Agency and the body in adolescent menstrual talk. Childhood, 12, 91110.

George, S. A. (2001). The Menopause Experience: A Woman's Perspective. Journal of Obstetric, Gynecologic, \& Neonatal Nursing, 31, 77-85. 
Johnston-Robledo, I., Ball, M., Lauta, K., \& Zekoll, A. (2003). To bleed or not to bleed: young women's attitudes toward menstrual suppression. Women Health, 38, 59-75.

Johnston-Robledo, I., \& Chrisler, J. (2013). The Menstrual Mark: Menstruation as Social Stigma. Sex Roles, 68, 9-18.

Kissling, E.A. (1996). Bleeding Out Loud: Communication about Menstruation. Feminism \& Psychology, 6, 481-504.

Koff, E., \& Rierdan, J. (1995). Preparing girls for menstruation: Recommendations from adolescent girls. Adolescence, 30, 795-812.

Lee, J. (2009). Bodies at Menarche: Stories of Shame, Concealment, and Sexual Maturation. Sex Roles, 60, 615-627.

Lindh-Åstrand, L., Hoffmann, M., Hammar, M., \& Kjellgren K. I. (2005). Women’s conception of the menopausal transition - a qualitative study. Journal of Clinical Nursing, 16, 509-517.

Lundgren, I., \& Berg, M. (2007). Central concepts in the midwife - woman relationship. Scandinavian Journal of Caring, 21, 220-228.

Marván, M.L., Ramírez-Esparza, D., Cortés-Iniestra, S., \& Chrisler, J.C. (2006). Development of a New Scale to Measure Belifs about and Attitudes Toward Menstruation (BATM): Data from Mexico and the United States. Health Care for Women International, 27, 453473.

Marván, M. L., \& Trujillo, P. (2010). Menstrual Socialization, Beliefs, and Attitudes Concerning Menstruation in Rural and Urban Mexican Women. Health Care for Women International, 31, 53-67.

McPherson, M., \& Korfine, L. (2004). Menstruation across time: menarche, menstrual attitudes, experiences, and behaviours. Women's Health Issues, 14, 193-200. 
O'Flynn, N. (2006). Menstrual symptoms: the importance of social factors in women's experiences. British Journal of General Practice, 56, 950-957.

Orringer, K., \& Gahagan, S. (2010). Adolescent Girls Define Menstruation: A Multiethnic Exploratory Study. Health Care for Women International, 31, 831-847.

Reece, E. A., \& Barbieri, R. L. (2010). Obstetrics and Gynecology: The Essentials of Clinical Care. Stuttgart and New York: Thieme.

Rembeck, G. I., \& Gunnarsson, R. K. (2004). Improving pre- and postmenarcheal 12-year-old girls' attitudes toward menstruation. Health Care for Women International, 25, 680-698.

Rembeck, G., \& Hermansson, E. (2008). Transition to Puberty as Experienced by 12-YearOld Swedish Girls. The Journal of School Nursing, 24, 326-334.

Riessman, C. K. (2008). Narrative Methods for the Human Sciences. Thousand Oaks: SAGE. Santer, M., Wyke, S., \& Warner, P. (2007). Women's management of menstrual symptoms: Findings from a postal survey and qualitative interviews. Social Science \& Medicine, 66, 276-288.

Shenton, A.K. (2004). Strategies for ensuring trustworthiness in qualitative research projects. Education for Information, 22, 63-75.

Sommer, M. (2009). Ideologies of sexuality, menstruation and risk: girls' experiences of puberty and schooling in northern Tanzania. Culture, Health \& Sexuality, 11, 383-398.

Stubbs, M.L., \& Costos, D. (2004). Negative Attitudes Toward Menstruation: Implications for Disconnection Within Girls and Between Women. Women \& Therapy, 27, 37-54.

Swedish Code of Statutes. (2003). The Act Concerning the Ethical Review of Research Involving Humans. SFS 2003:460. Retrieved from http://www.epn.se/start/startpage.aspx Törrönen, J. (2009). Semiotic theory on qualitative interviewing using stimulus texts. Qualitative Research, 2, 343-362. 
Uskul, A. K. (2004). Women's menarche stories from a multicultural sample. Social Science \& Medicine, 59, 667-679.

Yamamoto, K., Okazaki, A., Sakamoto, Y., \& Funatsu, M. (2009). The relationship between premenstrual symptoms, menstrual pain, irregular menstrual cycles, and psychosocial stress among Japanese college students. Journal of Physiological Anthropology, 28, 12936.

World Medical Association (2009). Declaration of Helsinki - Ethical Principles for Medical Research Involving Human Subjects. Retrieved from http://www.wma.net/en/30publications/10policies/b3/index.html 
Table 1 Themes that emerged from the Analysis

\begin{tabular}{cl}
\hline \multicolumn{1}{c}{ Themes } & \multicolumn{1}{c}{ Sub-themes } \\
\hline Belonging and Confidence & $\begin{array}{l}\text { Menstrual support and knowledge } \\
\text { Female bonding }\end{array}$ \\
Intimacy and Concealment & $\begin{array}{l}\text { Being exposed } \\
\text { To have but to hide } \\
\text { Affecting daily life }\end{array}$ \\
Menstruation as a Part of Life & $\begin{array}{l}\text { Assurance of a functioning body } \\
\text { A continuous process over time } \\
\text { Accepting menstruation }\end{array}$ \\
\hline
\end{tabular}

